\title{
False Cord Retractor: An important Tool in diagnosing Posterior Laryngeal Cleft
}

\author{
${ }^{1}$ Renuka Bradoo, ${ }^{2}$ Varun J Dave, ${ }^{3}$ Anagha Joshi, ${ }^{4}$ Kshitij Shah
}

\begin{abstract}
When the tracheoesophageal septum fails to develop or fuse, a laryngeal cleft is formed. It may or may not be associated with a tracheoesophageal fistula. Diagnosing a laryngeal cleft is not straightforward as was found to be in this case. Here, the cleft was masquerading as a laryngeal polyp, which resulted in misdiagnoses and delay in the management. A false cord retractor was of significant help in diagnosing the cleft. We recommend the use of this instrument during evaluation of laryngobronchoscopy in all patients suspected to have a laryngeal cleft.
\end{abstract}

Keywords: False cord retractor, Larungeal cleft, Tibial periosteum.

How to cite this article: Bradoo R, Dave VJ, Joshi A, Shah K. False Cord Retractor: An important Tool in diagnosing Posterior Laryngeal Cleft. Int J Phonosurg Laryngol 2017;7(1):20-22.

\section{Source of support: Nil}

Conflict of interest: None

\section{INTRODUCTION}

Laryngeal cleft is a rare congenital anomaly resulting from faulty development or fusion of the tracheoesophageal septum. Recurrent aspiration and subsequent pneumonia with failure to thrive are common complaints and in severe cases, it presents as a medical emergency which then requires intubation or tracheostomy. The laryngeal cleft may not be obvious on routine diagnostic endoscopy.

Lindholm's false cord retractor is an indispensable tool to have while diagnosing such patients. While dealing with the small pediatric larynges, the false cord retractor greatly enhances the surgeon's view and reduces the probability of a missed or faulty diagnosis.

\section{CASE REPORT}

A 2-month-old male patient was referred to the pediatric intensive care unit at our hospital with complaints of

\footnotetext{
${ }^{1}$ Professor and Head, ${ }^{2}$ Senior Registrar, ${ }^{3}$ Associate Professor ${ }^{4}$ Assistant Professor

${ }^{1-4}$ Department of ENT, Lokmanya Tilak Municipal General Hospital, Mumbai, Maharashtra, India

Corresponding Author: Varun J Dave, Senior Registrar Department of ENT, Sion Hospital, Mumbai, Maharashtra, India Phone: +919727747714, e-mail: varundavejay@gmail.com
}

stridor since birth and endotracheal tube in situ and inability to maintain oxygen saturation since 2 days. On eliciting history, it was found that the patient was delivered by cesarean section in view of the umbilical cord around his neck seen on ultrasonography. Patient had stridor at birth which was relieved in prone position along with breathlessness. Fiberoptic laryngoscopy was done in a private hospital which was suggestive of laryngomalacia. Patient was intubated and given ventilatory support for 6 days. Weaning was attempted but was unsuccessful and hence was referred to our hospital.

Patient was reintubated as blockage of tube was suspected and put on ventilatory support again because of respiratory distress and inability to maintain oxygen saturation. High-resolution computed tomography chest was done which revealed air bronchogram in the upper lobe of right lung, suggesting aspiration pneumonia. Primary check bronchoscopy was done which showed omega-shaped epiglottis, granulation tissue in the interarytenoid region, and tracheomalacia. Both vocal cords were normal and mobile. As long-term ventilator support was anticipated, patient was tracheostomized with portex number 3 tracheostomy tube. Weaning was attempted again but the patient was breathless again and started aspirating feeds.

At 6 months of age, repeat bronchoscopy was done, which showed a polypoidal mass protruding into the laryngeal lumen from the interarytenoid region superiorly (Fig. 1). This mass extended up to the subglotiss inferiorly.

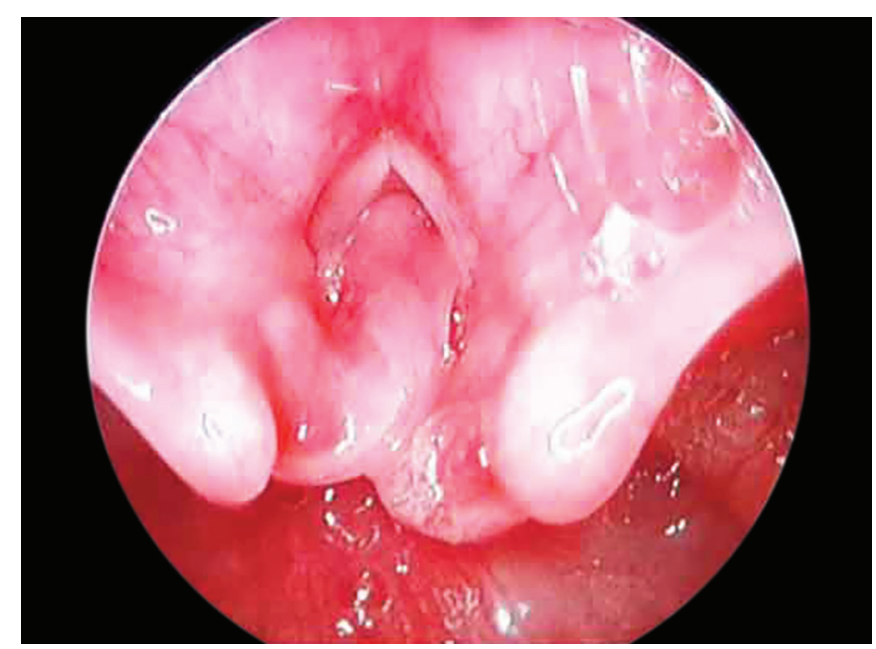

Fig. 1: Polypoidal mass in the posterior larynx 


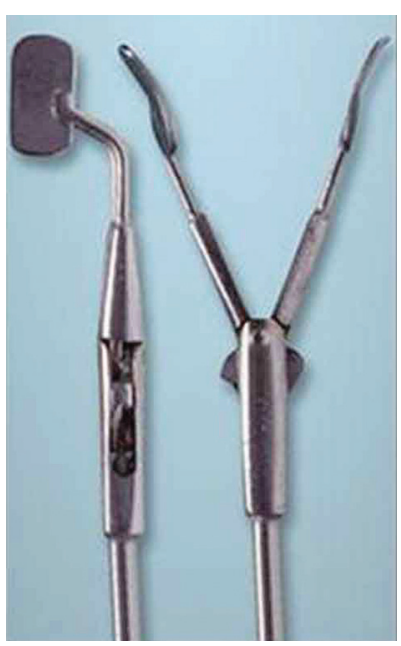

Fig. 2: Lindholm's false cord retractor

A punch biopsy was performed which showed normal respiratory mucosa.

In view of no definitive diagnosis and persistent aspiration, a detailed evaluation bronchoscopy was planned. This time, a false cord retractor was used to see the origin of the polypoidal mass. False cord retractor (Fig. 2) was inserted under vision and placed between the arytenoids.

As the arytenoids were separated, the polypoidal mass retracted back posteriorly (Fig. 3 and Video 1).

The diagnosis of "posterior laryngeal cleft with prolapsing normal mucosa" was made. It was similarly traced downward up to the subglottis. It was a type III laryngeal cleft. ${ }^{1}$

Patient was then operated for the cleft using the anterior laryngofissure approach. Tibial periosteum was used as an autograft and kept in the cleft and mucosa sutured over it on both sides. Immediate postoperative recovery was uneventful and the patient showed gradual increase in weight and there was no aspiration or breathlessness. Patient was accepting feeds well. He was weaned off the ventilator and breathed room air satisfactorily. ${ }^{2}$

\section{DISCUSSION}

Embryologically, the trachea and esophagus share a common lumen until they are separated by the tracheoesophageal septum. Failure of development of this tracheoesophageal septum or incomplete fusion leads to development of laryngeal cleft, which may or may not be associated with tracheoesophageal fistula. Laryngeal cleft is very rare, with an incidence of 1 in 20,000 live births. It is more common in boys with a ratio of $5: 3$ as compared with girls. Autosomal-dominant pattern of inheritance is proposed and prematurity and polyhydramnios have been found to be associated factors.

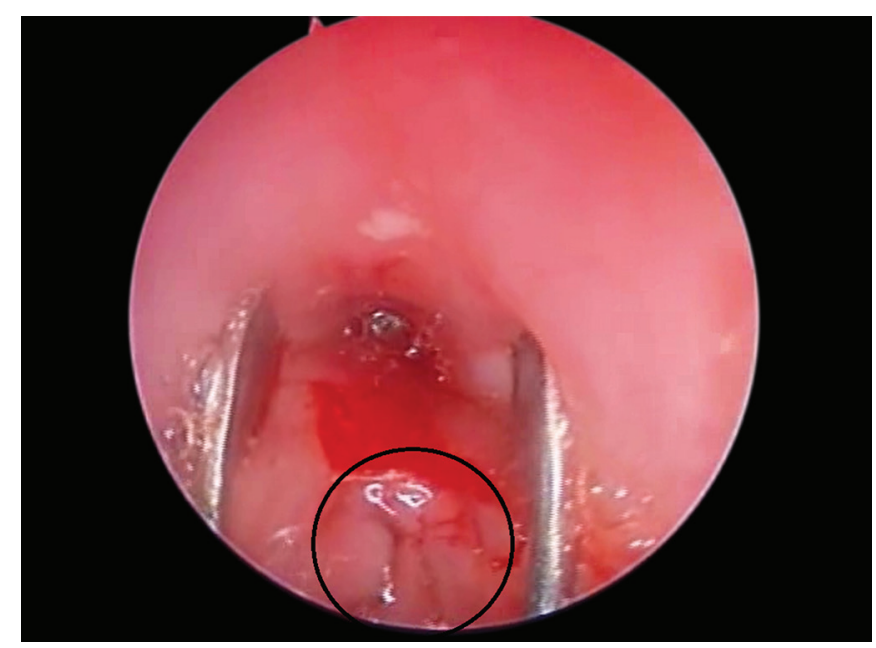

Fig. 3: Cleft seen clearly

Table 1: Classification of laryngeal clefts

\begin{tabular}{|c|c|}
\hline Type & Feature \\
\hline I & Cleft is located above the level of the vocal folds \\
\hline II & $\begin{array}{l}\text { Cleft extends below the vocal folds and into the upper } \\
\text { cricoid cartilage }\end{array}$ \\
\hline III & $\begin{array}{l}\text { Cleft extends through the cricoid cartilage and possibly } \\
\text { into the cervical trachea }\end{array}$ \\
\hline IV & $\begin{array}{l}\text { Cleft extends into the thoracic trachea and extends } \\
\text { variably toward the tracheal carina }\end{array}$ \\
\hline
\end{tabular}

Benjamin and Inglis ${ }^{1}$ classified the laryngeal cleft into four types (Table 1).

Diagnosing a laryngeal cleft requires a high index of suspicion in a patient who presents with stridor and breathlessness at birth and frequent aspiration and refusal to feeds. Microlaryngoscopy under general anesthesia is the gold standard for diagnosing laryngeal clefts. But diagnosing it is not always straightforward; it can be deceptive and misleading as it was in this case.

Here the cleft was obscured by prolapsing normal laryngeal mucosa and the condition was disguised as a polypoid mass in the posterior laryngeal cavity. We missed the cleft on primary evaluation which led to delayed diagnosis and subsequently delay in definitive treatment. Here, the use of Lindholm false cord retractor proved to be instrumental in separating the redundant mucosa and detecting the cleft.

Professor Carl Lindholm, a pioneer laryngologist, was the first to devise the instrument. The cord retractor or the laryngeal distending forceps is placed in inverted position on the false cords and opened to visualize the larynx. Longstreet et $\mathrm{al}^{3}$ conducted a quantitative study where they proved that laryngeal distending forceps increased the glottic opening by a mean of $359 \%$ and increased visualized true vocal cord area by $337 \%$. Angle at the anterior commissure increased from a mean of $24.9^{\circ}$ 
to a mean of $71.5^{\circ}$. Thus, these forceps greatly increase the visualization area of the superior surface of the vocal folds, posterior laryngeal cavity, anterior commissure, and the subglottis. The improved visualization of these structures enhances the ability of the surgeon to correctly diagnose and treat lesions that may be otherwise hidden. ${ }^{4}$

It is also used in diagnosis of other diseases, such as recurrent respiratory papillomatosis, glottic webs, subglottic stenosis, proximal tracheal lesions, and airway hemangioma. ${ }^{4}$

Thus, the false cord retractor is an essential instrument to have in the laryngologist's arsenal.

\section{CONCLUSION}

Laryngeal cleft may masquerade as a laryngeal polyp or remain undiagnosed. The false cord retractor is an indispensable tool to have in the laryngologist's armamentarium to ensure diagnosis of this condition.

\section{REFERENCES}

1. Benjamin B, Inglis A. Minor congenital laryngeal clefts: diagnosis and classification. Ann Otol Rhinol Laryngol 1989 Jun;98(6):417-420.

2. Bakthavachalam S, Schroeder JW, Holinger LD. Diagnosis and management of type I posterior laryngeal clefts. Ann Otol Rhinol Laryngol 2010 Apr;119(4):239-348.

3. Longstreet B, Bhama PK, Inglis AF Jr, Saltzman B, Perkins JA. Improved airway visualization during direct laryngoscopy using self-retaining laryngeal retractors: a quantitative study. Otolaryngol Head Neck Surg 2011 Aug;145(2):270-275.

4. Gallagher, TQ.; Hartnick, CJ. Direct laryngoscopy and rigid bronchoscopy. In: Hartnick CJ, Hansen MC, Gallagher TQ, editors. Pediatric airway surgery. Adv Otorhinolaryngol. Vol. 73. Basel: Karger; 2012. p 19-25. 